\title{
An unforgettable congress
}

The $12^{\text {th }}$ International Conference of the Asian Congress of Neurological Surgeons (ACNS)

\section{Onciul Razvan ${ }^{1}$, A.V.Ciurea ${ }^{2}$}

${ }^{1}$ Stud. 6th year, "Carol Davila, University of Medicine and Pharmacy, Bucharest, ROMANIA ${ }^{2}$ Neurosurgery Department Sanador Hospital, Bucharest; "Carol Davila” U.M.Ph., Bucharest, ROMANIA

All congresses organized in Dubai as a preferential location have an exceptional quality standing, due to the exotic location conditions with all the possible facilities at this time. For many years Dubai has been concentrating many medical activities symposiums, conferences, congresses due to the organizational standard, and why not, the extraordinarily pleasant climate in the winter months in Europe.

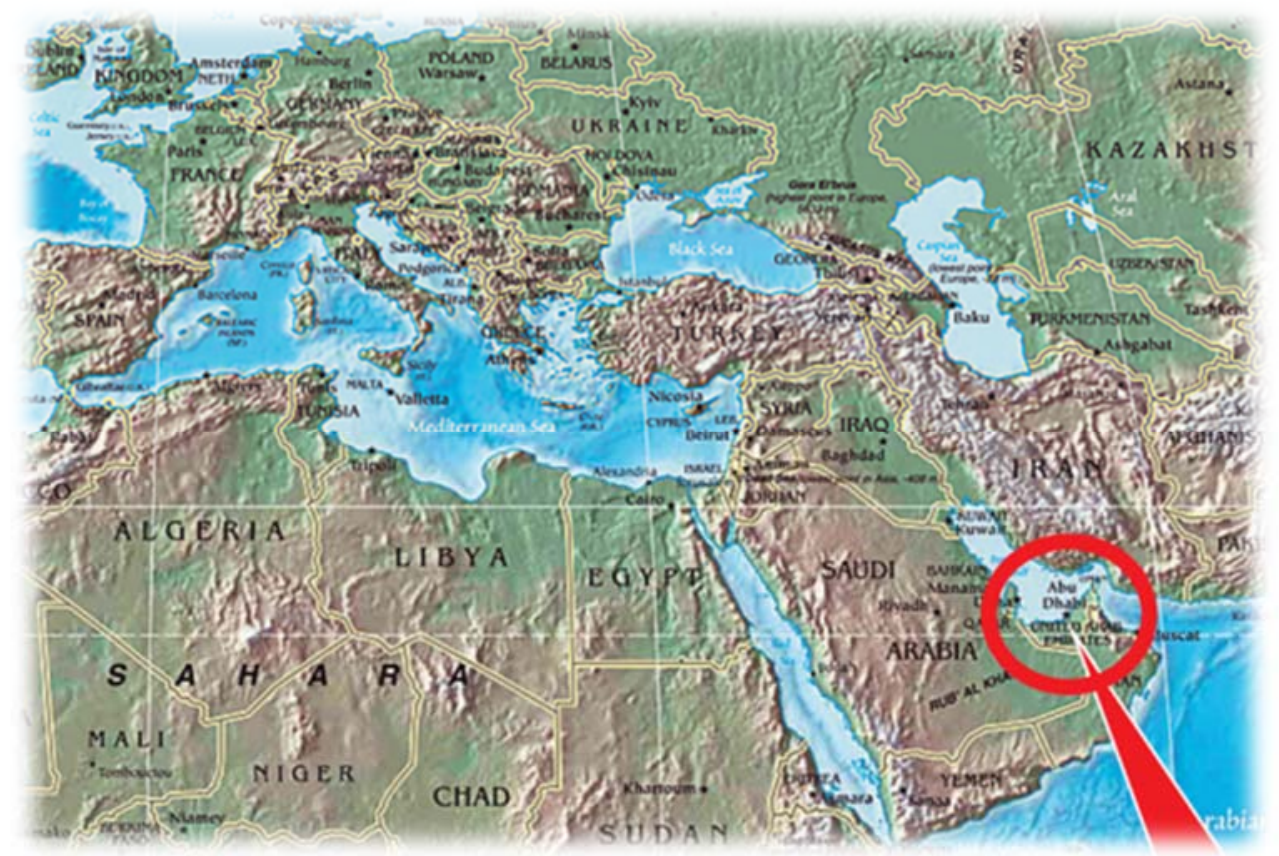


The ACNS Congress started with an initiative by Professor Tetsuo Kanno, who in 1993 made Toyota the first such congress as a Congress of Neurological Surgeons Surgeons (CNS) that takes place annually in the US. The extraordinary idea of Japanese teacher Tetsuo Kanno was immediately adopted by almost all states with neurosurgical activities in Asia. Thus, after the first congress implementation in recognized neurosurgical locations like Osaka and Nagoya, ACNS conquered other locations in Jakarta, Mumbai, Kula Lumpur, with the 12th congress being held in Dubai.

The organizer and president of the XIIth Congress appointed by ACNS was Professor Imad N. Kanaan who works in Saudi Arabia and opened an exceptional gateway to the Gulf countries. The topics were neuroanatomy, neuro-oncology, cerebrovascular, skull-base \& pituitary, neuroendoscopy, spine \& peripheral nerves, pediatric neurosurgery, stereotactic \& functional neurosurgery, neuro-trauma \& cristical care, neurosurgeons, research, education and innovation, ethics and socioeonomics covering the whole neurosurgical pathology and the significant number of invited speakers (143) have raised the scientific quality of this outstanding manifestation.

A number of works in the areas of intracranial anaevrisms: Yoko Kato and Jacques Morcos, endoscopy: H. Schroeder and F. Gentili, brain tumors: Isabelle Germano and Natale Fracaviglia, craniofaringiomas: J. Steno and C. Deopujari, brain tumors in children: Mourice Chux, spine surgery: R. Delfini, skull base surgery: Sebastien Froehlich, M. Ammirati, Anil Nanda and traumatology: F. Servadei, I. Cerian have been highlighted.

Accomodation was made at the Grand Hayat Hotel in extraordinary conditions and had over 500 participants from different countries, all under the aegis of the world's neurosurgery federation. (W.F.N.S.)

According to the president's presentation, the motto of the congress was "inspiration and innovation". The inspiration was due to the numerous presentations made by recognized personalities and the innovation was brought about by the major elements of technology in neuroimage and neurochirurgical interventions.

The Romanian delegation had three participants Prof. Dr. Stefan Florian, Prof. Dr. A.V. Ciurea, Dr. Alex Florian. In terms of presentations Prof. Dr. Stefan Florian had two speeches: "Brainstem tumors - How to approach" and "Complications of AVM surgery" and Prof. Dr. A.V. Ciurea also had two presentations: "New trends in aneurysm management in Romania" and "New gains in medulloblastoma in children (1992-2017) Can it be cured?". All these four papers raised the general interest, being appreciated in plenary. Dr. Alexandru Florian presented an extremely interesting work on "Brainstem cavernomas in infancy case reports", an extremely rare pathology at this age.

The preconference workshop consisted of the neuroendoscopy module, the spine module and the neuroanatomy module and the skull base, which also had an 
extraordinary audience on the part of the neurosurgery residents in the Arab countries.

Overall, we believe that this congress has fully achieved its goal of, on the one hand, an international opening of neurosurgical activity with the combination of procedures in this field, of ASIA teams, especially with those in Europe, on the other hand, a model of elegance and attitude in addressing the various topics discussed and debated lately, especially from vascular pathology (Coils vs Clipps) and oncological Skull Base pathology.

In the end, any national participation in such a congress is mandatory in order to reveal the neurochirurgical centers in Romania and to know the experience in this field of other acknowledged world neurosurgery centers. 